\title{
Does anesthetic provide similar neuroprotection to therapeutic hypothermia after cardiac arrest?
}

\author{
Hong Zhang ${ }^{* 1,2}$ \\ See related research by Meybohm et al., http://ccforum.com/content/14/1/R21
}

\begin{abstract}
In the previous issue of Critical Care, Meybohm and colleagues provide evidence to support hypothermia as a kind of therapeutic option for patients suffering cardiac arrest. Although anesthetics had been used to induce hypothermia, sevoflurane post-conditioning fails to confer additional anti-inflammatory effects after cardiac arrest. Further research in this area is warranted.
\end{abstract}

Therapeutic hypothermia has been shown to provide neuroprotection against ischemic injury after cardiac arrest in in vitro and in vivo models. In the previous issue of Critical Care, Meybohm and colleagues [1] demonstrate that cardiac arrest triggers the release of cerebral inflammatory cytokines in pigs' cerebral cortex. Therapeutic hypothermia alters inflammatory response in cardiac arrest and subsequent cardiopulmonary resuscitation. The combination of hypothermia with sevoflurane post-conditioning does not confer additional antiinflammatory effects compared with hypothermia alone.

Cardiac arrest remains the leading cause of death in the US and Europe, with an out-of-hospital cardiac arrest survival-to-discharge rate of less than 10\%. In-hospital cardiac arrest presents a dismal prognosis. According to a large in-hospital registry, the survival-to-discharge rate is $18 \%$, whereas that of a developing country is $6.9 \%[2,3]$. Without prompt care, the chance for meaningful survival falls dramatically within minutes of arrest onset. When immediate care is available and victims are successfully resuscitated, the majority of these initial survivors subsequently suffer crippling neurologic injury or die in the few days following the cardiac arrest event. Thus, improving survival and brain function after initial

\footnotetext{
*Correspondence: Hong Zhang, zhangh9@yahoo.com

'Department of Neurology, Zhongnan Hospital of Wuhan University, 169 Donghu Road, Wuhan 430071, China. ${ }^{2}$ Center for Cerebral Vascular Diseases, Medical College of Wuhan University, 169 Donghu Road, Wuhan 430071, China
}

resuscitation from cardiac arrest remains a critical challenge. Therapeutic hypothermia, introduced more than six decades ago, remains an important neuroprotective factor in cardiac arrest. Laboratory studies have demonstrated that cooling after resuscitation from cardiac arrest improves both survival as well as subsequent neurologic and cardiac function and has few side effects. These findings have been reproduced using a variety of cooling techniques in different species, including rats, dogs, and pigs.

However, physician use of hypothermia induction in patients resuscitated from cardiac arrest is low. In 2003, Abella and colleagues [4] reported that $87 \%$ of US physicians did not use therapeutic hypothermia following cardiac arrest. Various reasons for non-use were cited: $49 \%$ felt that there were not enough data, 32\% mentioned lack of incorporation of hypothermia into advanced cardiovascular life support protocols, and $28 \%$ felt that cooling methods were technically too difficult or too slow. In 2002, a European group demonstrated an improvement in survival-to-discharge rate with favorable neurologic status in cooled patients, compared with normothermic patients surviving after cardiac arrest ( $53 \%$ versus $35 \%$, respectively), and with no significant adverse events from cooling; thereafter, induced hypothermia was considered the best practice for patients following cardiac arrest [5]. In 2005, the American Heart Association recommended the consideration of therapeutic hypothermia for unconscious adult patients with return of spontaneous circulation following out-ofhospital cardiac arrest due to ventricular fibrillation. In 2008, Binks and colleagues [6] reported that $85.6 \%$ of intensive care units in the UK were using hypothermia as part of post-cardiac arrest management.

Clinical observation demonstrated that tumor necrosis factor-alpha (TNF $\alpha$ ) and interleukin-6 (IL-6) protein were increased in cerebrospinal fluid following cardiac arrest [7]. Animal studies showed that inflammatory markers were unregulated in rats' hippocampus tissue and pigs' serum and myocardial tissue after cardiac arrest [8-10]. Meybohm and colleagues [1] go further to demonstrate anti-inflammatory and anti-apoptosis effects 
of therapeutic hypothermia via the reduction of the upregulation expression of IL-1 $\beta$, IL- 6 , IL-10, TNF $\alpha$ and intercellular adhesion molecule-1, Bcl-2, and Bax mRNA and IL- $1 \beta$ protein in cerebral cortex after cardiac arrest in a pig model.

Small reductions in core temperature lead to vasoconstriction and shivering, effectively hindering hypothermia. Thus, prevention of vasoconstriction and shivering has become a major goal during induction of therapeutic hypothermia. Anesthetics and sedatives can lower the vasoconstriction and shivering threshold, thus allowing hypothermia. Sevoflurane pre-conditioning and early post-conditioning reduced both cerebral infarct size and neurological defect score, reduced impairment of hippocampus long-term potentiation resulting from myocardial ischemia, and increased nuclear factor inhibitory kappaBalpha content in THP-1 cells [11-13]. Sevoflurane pre-conditioning preserves myocardial function in patients undergoing coronary artery bypass graft surgery under cardiologic arrest [14]. An in vivo study showed that combination hypothermia with sevoflurane attenuates the inflammatory response during endotoxemia [15]. However, Meybohm and colleagues [1] could not provide evidence to support the view that sevoflurane post-conditioning confers additional antiinflammatory effects in pigs' cerebral cortex after cardiopulmonary resuscitation.

In summary, Meybohm and colleagues [1] provide useful evidence to support the clinical use of therapeutic hypothermia for cardiac arrest, but they did not study the anti-inflammatory effects of sevoflurane in this model. It is even possible that in the setting of clinical practice, anesthetics may not provide significant neuroprotection beyond that which is already being produced by therapeutic hypothermia. Thus, at this time, it is difficult to recommend anesthetics for the purpose of neuroprotection in cardiac arrest.

\section{Abbreviations}

IL, interleukin; TNFa, tumor necrosis factor-alpha.

\section{Competing interests}

The author declares that he has no competing interests.

Published: 8 April 2010

\section{References}

1. Meybohm P, Gruenewald M, Zacharowski KD, Albrecht M, Lucius R, Fösel N, Hensler J, Zitta K, Bein B: Mild hypothermia alone or in combination with anesthetic postconditioning reduces expression of inflammatory cytokines in the cerebral cortex of pigs after cardiopulmonary resuscitation. Crit Care 2010, 14:R21.

2. Sugerman NT, Abella BS: Hospital-based use of therapeutic hypothermia after cardiac arrest in adults. J Neurotrauma 2009, 26:371-376.

3. Suraseranivongse $S$, Chawaruechai T, Saengsung P, Komoltri C: Outcome of cardiopulmonary resuscitation in a 2300-bed hospital in a developing country. Resuscitation 2006, 71:188-193.

4. Abella BS, Rhee JW, Huang KN, Vanden HoekTL, Becker LB: Induced hypothermia is underused after resuscitation from cardiac arrest: a current practice survey. Resuscitation 2005, 64:181-186.

5. Hypothermia After Cardiac Arrest Study Group: Mild therapeutic hypothermia to improve the neurologic outcome after cardiac arrest. NEngl J Med 2002, 346:549-556.

6. Binks AC, Murphy RE, Prout RE, Bhayani S, Griffiths CA, Mitchell T, Padkin A, Nolan JP: Therapeutic hypothermia after cardiac arrest-implementation in UK intensive care units. Anaesthesia 2010, 65:260-265.

7. Youngquist ST, Niemann JT, Heyming TW, Rosborough JP: The central nervous system cytokine response to global ischemia following resuscitation from ventricular fibrillation in a porcine model. Resuscitation 2009, 80:249-252.

8. Teschendorf P, Albertsmeier M, Vogel P, Padosch SA, Spöhr F, Kirschfink M, Schwaninger M, Böttiger BW, Popp E: Neurological outcome and inflammation after cardiac arrest--effects of protein $C$ in rats. Resuscitation 2008, 79:316-324.

9. Sipos W, Duvigneau C, Sterz F, Weihs W, Krizanac D, Bayegan K, Graf A, Hartl R, Janata A, Holzer M, Behringer W: Changes in interleukin-10 mRNA expression are predictive for 9-day survival of pigs in an emergency preservation and resuscitation model. Resuscitation 2010 Feb 16. [Epub ahead of print].

10. Meybohm P, Gruenewald M, Albrecht M, Zacharowski KD, Lucius R, Zitta K, Koch A, Tran N, Scholz J, Bein B: Hypothermia and postconditioning after cardiopulmonary resuscitation reduce cardiac dysfunction by modulating inflammation, apoptosis and remodeling. PLoS One 2009, 4:e7588.

11. Adamczyk S, Robin E, Simerabet M, Kipnis E, Tavernier B, Vallet B, Bordet R, Lebuffe G: Sevoflurane pre- and post-conditioning protect the brain via the mitochondrial K ATP channel. Br J Anaesth 2010, 104:191-200.

12. Zhu J, Jiang $X$, Shi $E, M a ~ H$, Wang J: Sevoflurane preconditioning reverses impairment of hippocampal long-term potentiation induced by myocardial ischaemia-reperfusion injury. Eur J Anaesthesio/ 2009, 26:961-968.

13. Boost KA, Leipold T, Scheiermann P, Hoegl S, Sadik CD, Hofstetter C, Zwissler $B$ : Sevoflurane and isoflurane decrease TNF-alpha-induced gene expression in human monocytic THP-1 cells: potential role of intracellular IkappaBalpha regulation. Int J Mol Med 2009, 23:665-671.

14. Julier K, da Silva R, Garcia C, Bestmann L, Frascarolo P, Zollinger A, Chassot PG, Schmid ER, Turina MI, von Segesser LK, Pasch T, Spahn DR, Zaugg M: Preconditioning by sevoflurane decreases biochemical markers for myocardial and renal dysfunction in coronary artery bypass graft surgery: a double-blinded, placebo-controlled, multicenter study. Anesthesiology 2003, 98:1315-1327.

15. Hofstetter C, Boost KA, Flondor M, Basagan-Mogol E, Betz C, Homann M, Muhl $H$, Pfeilschifter J, Zwissler B: Anti-inflammatory effects of sevoflurane and mild hypothermia in endotoxemic rats. Acta Anaesthesio/ Scand 2007, 51:893-899.

doi:10.1186/cc8923

Cite this article as: Zhang $\mathrm{H}$ : Does anesthetic provide similar neuroprotection to therapeutic hypothermia after cardiac arrest? Critical Care 2010, 14:137. 